\title{
Mouse Sycp1 functions in synaptonemal complex assembly, meiotic recombination, and $X Y$ body formation
}

\author{
Femke A.T. de Vries, ${ }^{1,5}$ Esther de Boer, ${ }^{2,5}$ Mike van den Bosch, ${ }^{1}$ Willy M. Baarends, ${ }^{3}$ Marja Ooms, ${ }^{3}$ \\ Li Yuan, ${ }^{4}$ Jian-Guo Liu, ${ }^{4}$ Albert A. van Zeeland, ${ }^{1}$ Christa Heyting, ${ }^{2,6}$ and Albert Pastink ${ }^{1,7}$ \\ ${ }^{1}$ Department of Toxicogenetics, Leiden University Medical Centre, 2333 AL Leiden, The Netherlands; ${ }^{2}$ Molecular Genetics \\ Group, Wageningen University, 6703 BD Wageningen, The Netherlands; ${ }^{3}$ Department of Reproduction and Development, \\ Erasmus University Rotterdam, 3000 DR Rotterdam, The Netherlands; ${ }^{4}$ Center for Genomics and Bioinformatics, \\ Karolinska Institutet, S-171 77 Stockholm, Sweden
}

In meiotic prophase, synaptonemal complexes (SCs) closely appose homologous chromosomes (homologs) along their length. SCs are assembled from two axial elements (AEs), one along each homolog, which are connected by numerous transverse filaments (TFs). We disrupted the mouse gene encoding TF protein Sycp1 to analyze the role of TFs in meiotic chromosome behavior and recombination. Sycp1 ${ }^{-/-}$mice are infertile, but otherwise healthy. Sycp1 $1^{-/-}$spermatocytes form normal AEs, which align homologously, but do not synapse. Most Sycp $1^{-/-}$spermatocytes arrest in pachynema, whereas a small proportion reaches diplonema, or, exceptionally, metaphase I. In leptotene $S y c p 1^{-/-}$spermatocytes, $\gamma \mathrm{H} 2 \mathrm{AX}$ (indicative of DNA damage, including double-strand breaks) appears normal. In pachynema, Sycp1 ${ }^{-/-}$spermatocytes display a number of discrete $\gamma \mathrm{H} 2 \mathrm{AX}$ domains along each chromosome, whereas $\gamma \mathrm{H} 2 \mathrm{AX}$ disappears from autosomes in wild-type spermatocytes. RAD51/DMC1, RPA, and MSH4 foci (which mark early and intermediate steps in pairing/recombination) appear in similar numbers as in wild type, but do not all disappear, and MLH1 and MLH3 foci (which mark late steps in crossing over) are not formed. Crossovers were rare in metaphase I of Sycp1 $1^{-/-}$mice. We propose that SYCP1 has a coordinating role, and ensures formation of crossovers. Unexpectedly, Sycp1 ${ }^{-/-}$spermatocytes did not form XY bodies.

[Keywords: XY body; chromosome pairing; meiosis; mouse; recombination; synaptonemal complex]

Supplemental material is available at http://www.genesdev.org.

Received November 1, 2004; revised version accepted April 18, 2005.

In meiosis, two rounds of chromosome segregation follow one round of replication. The first segregation, meiosis I, is reductional, as homologous chromosomes (homologs) move to opposite poles, whereas meiosis II is equational, because sister chromatids disjoin. The disjunction of homologs is prepared during the prophase of meiosis I, when homologs pair and nonsister chromatids of homologs recombine (for review, see Zickler and Kleckner 1999). The resulting crossovers and cohesion between the sister chromatids connect the homologs and ensure their proper disjunction at meiosis I. In most analyzed eukaryotes, meiotic recombination is accompanied by the close apposition of homologs by a zipper-like proteinaceous structure, the synaptonemal complex (SC). After premeiotic S-phase, the two sister chromatids of each chromosome develop a common axial structure,

\footnotetext{
${ }^{5}$ These authors contributed equally to this work. Corresponding authors.

${ }^{6}$ E-MAIL Christa.Heyting@wur.nl; FAX 91-(0)317-483140.

${ }^{7}$ E-MAIL A.Pastink@lumc.nl; FAX 31-(0)71-5276173.

Article and publication are at http://www.genesdev.org/cgi/doi/10.1101/ gad.329705.
}

the axial element (AE), which consists of a linear array of protein complexes involved in sister chromatid cohesion (cohesin complexes), associated with various additional proteins (for review, see Page and Hawley 2004). Numerous transverse filaments (TFs) then connect the AEs of two homologs (synapsis) to form an SC. Within the SC, AEs are called lateral elements (LEs).

Genes encoding TF proteins have been identified in mammals (Sycp1), budding yeast (ZIP1), Drosophila $(c(3) G)$, and Caenorhabditis (Syp-1 and Syp-2). SYCP1, Zip1, and C(3)G are long coiled-coil proteins with globular domains at both ends. Within SCs, they form parallel coiled-coil homodimers, which are embedded with their $\mathrm{C}$ termini in the LEs, whereas the $\mathrm{N}$ termini of TF protein molecules from opposite LEs overlap in the narrow region between the LEs of the two homologs. Caenorhabditis Syp-1 and Syp-2 are two short coiled-coil proteins, which possibly take the place of a single longer coiled-coil protein in other species (for review, see Page and Hawley 2004).

In the three species in which it has been analyzed, Drosophila, Caenorhabditis, and yeast, TF-deficient mu- 
tants still initiate meiotic recombination by induction of DNA double-strand breaks (DSBs) (Storlazzi et al. 1996; Colaiácovo et al. 2003; Jang et al. 2003), and align homologous chromosomes. However, they are deficient in crossover formation (for reviews, see Zickler and Kleckner 1999; Page and Hawley 2004). In Caenorhabditis and Drosophila, meiotic crossing over is abolished (Page and Hawley 2001; MacQueen et al. 2002; Colaiácovo et al. 2003), whereas in yeast zip1 null mutants, meiotic crossing over is reduced (Sym et al. 1993; Börner et al. 2004). Interestingly, Zip1 contributes to crossover formation even if no SC is assembled (Storlazzi et al. 1996), so not all functions of TF proteins in crossover formation require an intact SC structure; Storlazzi et al. (1996) proposed that Zip1 has a role in crossover designation before an SC is formed.

Börner et al. (2004) analyzed the crossover defect of yeast zip1 null mutants in detail. In wild-type yeast meiosis, DSB ends are resected so that 3 ' single-stranded tails arise (Sun et al. 1991). zip1 mutants show wild-type levels and kinetics of DSB formation and resection, but coordinate defects in later steps, namely, the formation of single end invasions (SEIs), double Holliday junctions (dHJs), and crossovers, which indicates that the progression from resected DSBs to SEIs is affected in zip1 mutants. Because in wild-type yeast SEIs appear in late zygonema (Hunter and Kleckner 2001), Zip1 fulfils its role in this step in crossover formation before an intact SC structure has been formed.

The relation between SC formation and recombination implies more than a requirement of TF proteins for crossing over. Synapsis and recombination are interdependent in most species, and the interdependency differs between species. In yeast and mouse, but not Drosophila, disruption of genes involved in meiotic DSB formation, resection, or strand invasion also affect synapsis, and most recombinational interactions in early meiosis probably serve to establish or stabilize homolog alignment and/or initiation of synapsis (for review, see Hunter 2003). Because of this interdependence it is important to analyze the localization of complexes of recombination-related proteins relative to the SCs/AEs in TF-deficient mutants. Such complexes can be recognized immunocytochemically (Anderson et al. 1997; Moens et al. 2002). Upon immunofluorescent labeling they are visible as foci by light microscopy. The composition of foci changes as meiotic prophase proceeds, which most likely directly or indirectly reflects successive steps in homolog alignment and recombination (for review, see Ashley and Plug 1998).

The mouse provides excellent opportunities for studying the role of TFs in chromosome pairing and recombination by an immunocytological approach, because the cytology of mouse meiosis is very well developed, and successive stages of meiosis can be determined precisely (for review, see Ashley 2004). Furthermore, several SC components, including TF protein SYCP1 (Meuwissen et al. 1992; Sage et al. 1995) and many recombination-related proteins have been identified in the mouse, and the localization of these proteins in mouse meiosis has been studied in great detail (Heyting and Dietrich 1991; Ashley and Plug 1998; Moens et al. 2002). We disrupted the Sycp1 gene and analyzed the effect of the disruption on male meiosis, following an immunocytochemical approach. We focused on the state of the AEs and the formation of foci containing recombination-related proteins in order to find out whether and how homolog alignment, meiotic recombination, and SC assembly are affected in Sycp1-/- mutants.

\section{Results}

\section{Targeted inactivation of Sycp1}

We disrupted the mouse Sycp 1 gene, using a targeting vector in which exon 2 to exon 8 of the gene had been replaced by a neomycin selection marker. The replaced sequence includes the splice donor sequence of intron 1 , the ATG start codon in exon 2 , and $\sim 20 \%$ of the Sycp 1 ORF (Fig. 1A). The targeting vector was linearized and electroporated into embryonic stem (ES) cells. We tested $\sim 600$ neomycin- and gancyclovir-resistant ES cell clones by PCR for correct targeting. About $2 \%$ of the clones

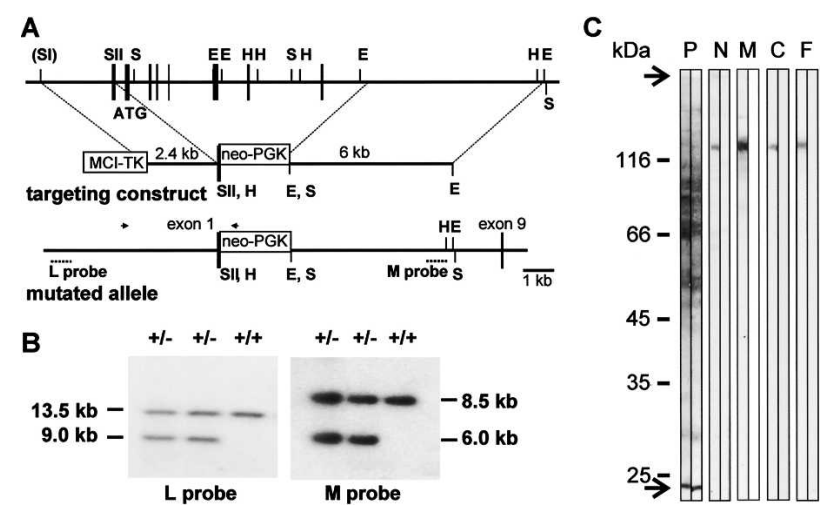

Figure 1. Targeted inactivation of mouse Sycp1. (A) Structure of the targeted region of the wild-type Sycp1 gene with exons 1-8 (top), targeting vector (center), and targeted allele (bottom). The ATG start codon is located in exon 2. Solid boxes indicate exons. Targeted integration results in a deletion including the 3 '-end of exon 1 and exons 2-8. (E) EcoRI; (B) BglII; (H) HindIII; (S) SphI; (SII) SacII. The SalI site indicated between brackets was derived from the $\lambda$ phage vector. Arrows indicate the primers used for screening for correctly targeted clones. $(B)$ Blot analysis of DNA from wild-type $(+/+)$ and heterozygous (+/-) ES cells digested with HindIII (left) and SphI (right) and hybridized with the $\mathrm{L}$ probe and the $\mathrm{M}$ probe, respectively. The wild-type 13.5$\mathrm{kb}$ HindIII fragment is replaced by a $9.0-\mathrm{kb}$ fragment in the mutant and the $8.5-\mathrm{kb} \mathrm{SphI}$ fragment from the wild-type allele by a $6.0-\mathrm{kb}$ fragment. (C) Western blot analysis of testis cell extracts from Sycp 1 ${ }^{-/-}$mice. Strips carrying proteins from testis cell extracts from heterozygous mice (left in each pair of strips) or Sycp 1-/- mice (right strip) were probed with antibodies against the $\mathrm{N}$-terminal $(\mathrm{N})$, middle $(\mathrm{M})$, or $\mathrm{C}$-terminal part $(\mathrm{C})$ of SCP1 (the rat protein homologous to SYCP1), or against nearly full-length SCP1 (F). (P) Ponceau S-stained strips. Arrows indicate the top of the gel and the electrophoresis front. (kDa) Molecular mass in kilodaltons. 
de Vries et al.

Figure 2. Morphology, histology, and TUNEL analysis of testes from Sycp $1^{-/-}$ mice. The histological sections were stained with hematoxilin and eosin. $(A-F)$ Testicular histology of adult Sycp $1^{-/-}(-/-$, $A, C, E)$ and $S y c p 1^{+/-}(+/-, B, D, F)$ mice. Note the total absence of post-meiotic germ cells in Sycp1 $1^{-/}$sections. Pachytene nuclei are abundant, but show aberrant nuclear morphology. (G-J) TUNEL analysis of testis sections of Sycp $1^{-/-}(-/-, G, I)$ and Sycp1 $1^{+-}(+/-, H, J)$ mice. Tubule sections with numerous TUNEL-positive nuclei occur only in $S y c p 1^{-/-}$mice. A few apoptotic nuclei are visible in tubule sections from Sycp $1^{+/-}$mice. $(K)$ Testes from Sycp $1^{+/-}(+/-)$and Sycp $1^{-/-}(-/-)$mice. Bars: $A-D, I, J, 50 \mu \mathrm{m} ; E, F, 25 \mu \mathrm{m} ; G, H, 100$ $\mu \mathrm{m} ; K, 2 \mathrm{~mm}$.
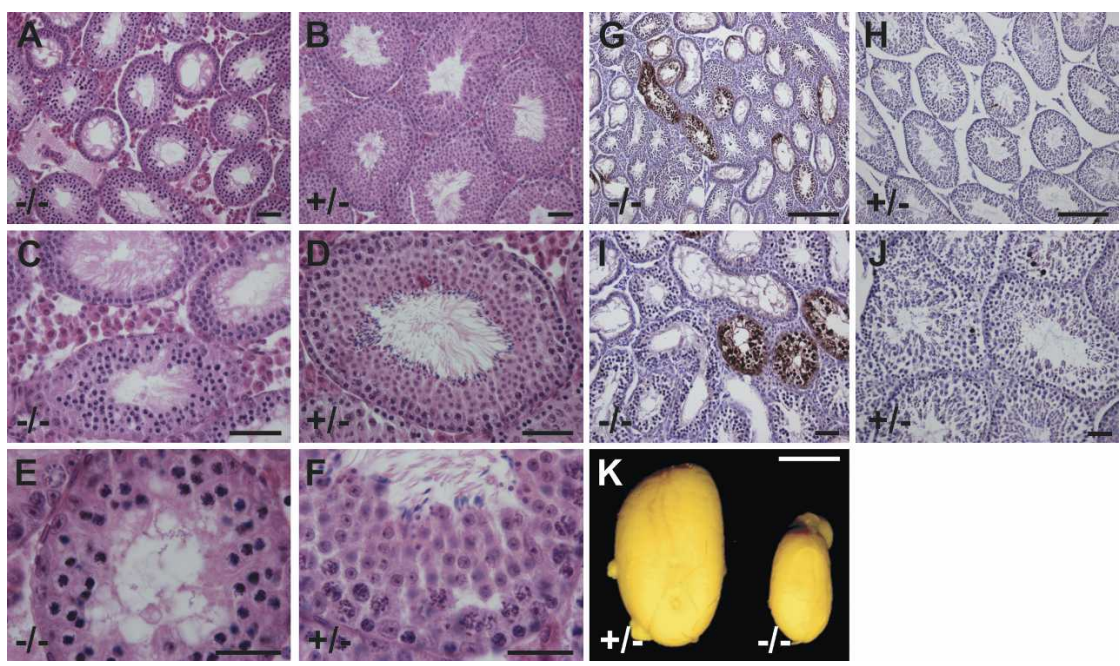

tested contained the disrupted Syсp1 allele. Correct targeting was confirmed by Southern blot analysis (Fig. 1B). We injected targeted ES clones into C57BL/6 blastocysts and obtained germline transmitting chimeric animals. Intercrosses of $S y c p 1^{+/-}$animals yielded $S y c p 1^{+/+}$, Sycp 1 ${ }^{+-}$, and Sycp $1^{-/-}$offspring in the expected Mendelian ratio. The Sycp1 $1^{-/-}$mice are viable and don't display obvious developmental defects. Antibodies against peptides covering the $\mathrm{N}$-terminal, middle, or $\mathrm{C}$-terminal part of SCP1 (the rat protein homologous to SYCP1), or against nearly full-length $\mathrm{SCP} 1$, did not bind to any proteins in testis cell extracts from Sycp $1^{-/-}$mice (Fig. 1C), indicating that these mice do not express truncated SYCP1. Most likely the SYCP1 disruption equals a null mutation.

\section{Sycp $1^{-/-}$mice are infertile}

Whereas $S y c p 1^{+/-}$mice were fully fertile, repeated breeding attempts of Sycp1 $1^{-/-}$males and females with wildtype animals did not yield any offspring. If the same wild-type animals were mated with heterozygous $\left(S y c p 1^{+/-}\right)$males or females, pregnancy was readily achieved. Sycp $1^{-/-}$testes and ovaries were much smaller than those of $S y c p 1^{+/-}$or wild-type mice (shown for testis in Fig. $2 \mathrm{~K}$ ), and Sycp $1^{-/-}$testes weighed on average $70 \%$ less than wild-type testes. Spermatozoa were lacking in epididymides of Sycp1 $1^{-/-}$knockout males (data not shown). SYCP1 is thus required for correct development of the reproductive organs and for male and female fertility.

Histological analysis of the gonads revealed various abnormalities. As is explained in detail in the Supplemental Material, the mouse testis is organized in seminiferous tubules, in which cells differentiate coordinately. The tubules from Sycp $1^{-/-}$mice were much smaller than those from wild type (Fig. 2A-F). They contained spermatogonia and spermatocytes, which appeared normal with respect to the presence of $\mathrm{AE} / \mathrm{LE}$ proteins SYCP2 and SYCP3 (see below; Supplemental Material), but the morphology of their nuclei was often abnormal. Furthermore, spermatocyte stages beyond dip-

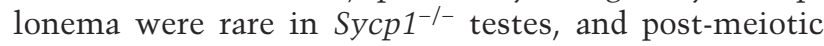
spermatogenic cells (spermatids and spermatozoa) were completely lacking. Apparently, spermatogenic differentiation is interrupted predominantly at the pachytene stage of $S y c p 1^{-/-}$spermatocytes, which most likely causes the sterility of $S y c p 1^{-/-}$males. However, as has been found in other mouse meiotic mutants, the organization of the seminiferous tubules was not disrupted and the residual spermatocytes in Sycp $1^{-/-}$mice formed associations with similar cell types (except spermatids) as the corresponding spermatocytes in wild type (Supplemental Material).

Sycp $1^{-/-}$ovaries weighed on average $35 \%$ less than Sycp $1^{+/-}$or Sycp $1^{+/+}$ovaries. Growing follicles and oocytes were lacking in sections of Sycp $1^{-/-}$ovaries, which suggests a disruption of oocyte development during meiosis, followed by apoptosis.

\section{SYCP1-deficiency leads to increased apoptosis during pachynema}

One possible explanation for the lack of spermatids in Sycp $1^{-/-}$testes is that spermatogenic cells enter apopto-

Figure 3. Assembly of AEs in Sycp $1^{-/-}$mice. $(A, B)$ Electron micrographs of AEs and SCs from wild-type $(+/+)$ and $S y c p 1^{-/-}(-/-)$male mice. (A) Wild-type SC with closely apposed AEs and a CE. (B) Homologously aligned AEs from a Sycp $1^{-/-}$spermatocyte, connected by AAs. $(C-J)$ Components of AEs and SCs in wild-type $(+/+)$ and $S y c p 1^{-/-}(-/-)$diplotene $(C, D)$ or pachytene $(E-J)$ spermatocytes; LE/AE protein SYCP3 and all analyzed cohesins are present in LEs/AEs of wild type and mutant, whereas SYCP1 is not detectable in mutant spermatocytes. $(K-T)$ Formation of AEs/LEs, as shown by REC8/SYCP3 double labeling, in wild-type $(+/+)$ and $S y c p 1^{-/-}(-/-)$spermatocytes. $(K, L)$ Early leptonema. $(M, N)$ Late leptonema. $(O, P)$ Zygonema. $(Q, R)$ Pachynema. $(S, T)$ Diplonema; note the XY bivalent $(\mathrm{XY})$ in wild-type cells $(Q, S)$, and separate $\mathrm{X}$ and $\mathrm{Y}$ chromosomes in the Sycp $1^{-1-}$ cells $(R, T)$. Bars: $A, B, 1 \mu \mathrm{m} ; C-T, 10 \mu \mathrm{m}$. 

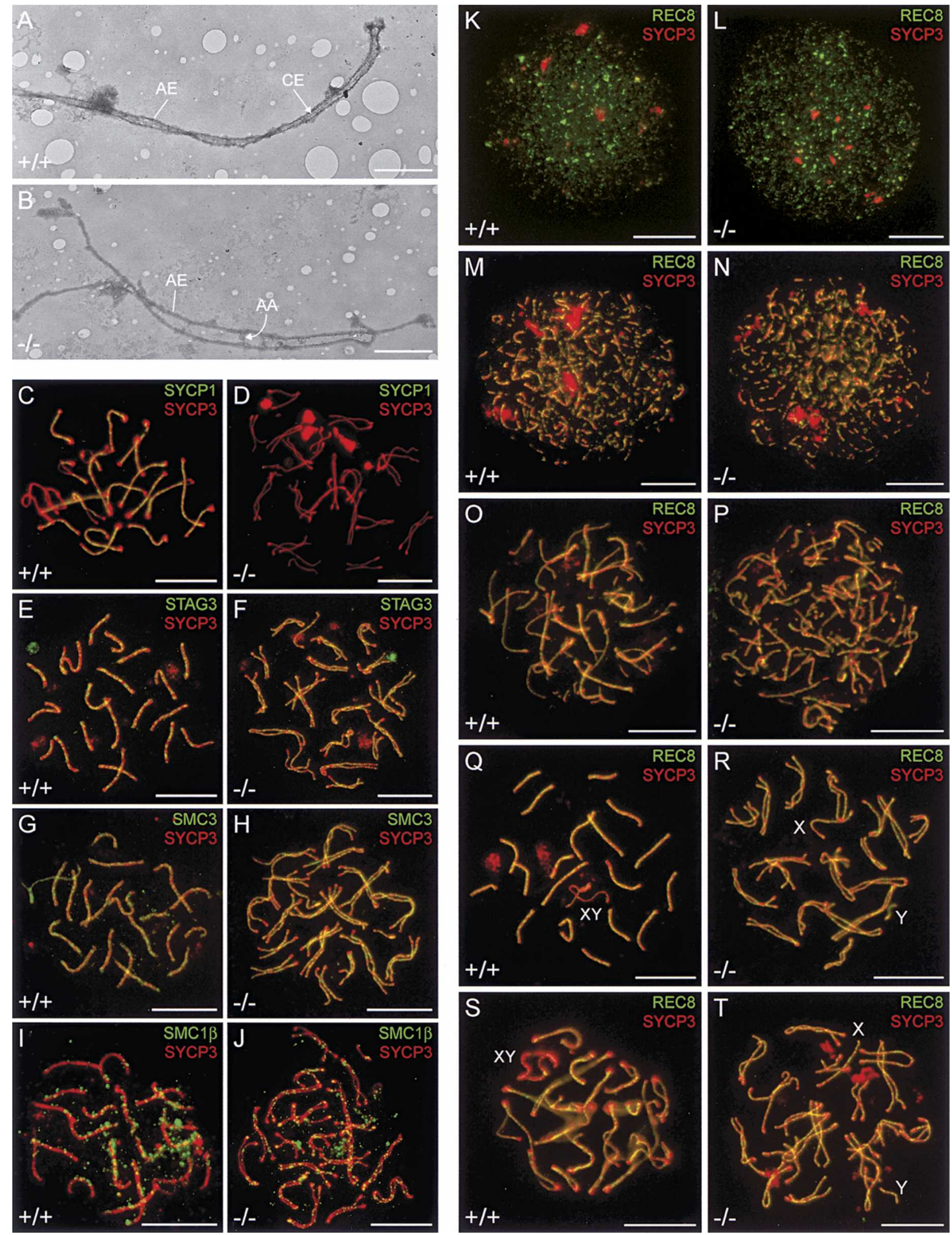

(Figure 3 legend on facing page.)

sis during meiotic prophase (for review, see de Rooij and de Boer 2003). We tested this using TUNEL analysis of testis sections from $\sim 8$-wk-old $S y c p 1^{+/-}$and Sycp $1^{-/-}$ mice. In $S y c p 1^{+/-}$testes, we found on average 0.7 apo- 
ptotic nuclei per cross-sectioned tubule, which is slightly more than previously found in wild type (Baarends et al. 2003). In Sycp $1^{+/-}$testes, the TUNELpositive cells were most often in pachynema or metaphase/anaphase I (Fig. 2G-J). In testis sections of Sycp $1^{-/-}$but not of Sycp $1^{+/-}$animals, certain tubules contained many (10 or more) apoptotic nuclei. Accordingly, the percentage of tubule sections with five or more apoptotic nuclei had almost doubled in Sycp $1^{-/-}$compared with $S y c p 1^{+/-}$testes $(20 \%$ vs. $11 \%)$. Because the percentage of tubules without apoptotic nuclei had not changed, we think that apoptosis occurs at similar developmental steps in Sycp $1^{-/-}$animals as in wild type, but with a highly increased incidence, resulting in Sycp $1^{-/-}$tubules containing a whole layer of apoptotic nuclei. Thus, in $S y c p 1^{-/-}$males, spermatogonia enter meiotic prophase, but most spermatocytes die of apoptosis at pachynema, and exceptionally some get to metaphase I.

\section{AEs are formed in the absence of SYCP1 and align homologously}

Sycp $1^{-/-}$spermatocytes assemble morphologically normal AEs (Fig. 3), which align homologously (Fig. 3; Supplementary Fig. S1), but are not connected by TFs, and do not show a central element between them, i.e., they do not synapse (Fig. 3B). In Sycp $1^{-/-}$spermatocytes, AEs are only connected by a limited number of axial associations (AAs) (Fig. 3A,B), and are farther apart $(211 \pm 17 \mathrm{~nm}$ at AAs) than the LEs in pachytene spermatocytes of wild type (in agar filtrates: $79 \pm 3 \mathrm{~nm}$ ). This resembles the yeast zip1 phenotype (Sym et al. 1993), including the size of the AAs, and is consistent with the idea that SYCP1 is a TF component. Beyond the most centromere proximal and distal AAs, the AEs tend to be somewhat wider apart, so the AAs are the only or at least the shortest connections between the AEs. All analyzed components of wild-type mouse AEs/LEs were also present in Sycp1 1/- AEs (Fig. 3; for SYCP2, see Fig. 4).

In the Supplemental Material we present evidence that the order of Sycp $1^{-/-}$and wild-type spermatocyte stages, as defined by AE morphology and extent of alignment/ synapsis, is the same (Supplementary Figs. S2, S3), and that corresponding $S y c p 1^{-/-}$and wild-type stages have similar life spans, at least until the spermatocytes enter apoptosis. We use, therefore, AE morphology and alignment/synapsis as criteria for staging and comparing Sycp $1^{-/-}$and wild-type spermatocytes. The assembly and alignment of AEs, as detected by REC8/SYCP3 double labeling, proceeds similarly in Sycp $1^{-/-}$and wild type (Fig. 3K-T). The pseudo-autosomal parts of the $\mathrm{X}$ and $\mathrm{Y}$ chromosome, however, were not aligned in $28 \%$ of the Sycp $1^{-/-}$pachytene cells, whereas they were synapsed in $100 \%$ of the wild-type pachytene cells (examples shown in Figs. 3, 4). Although most Sycp $1^{-/-}$spermatocytes are lost during pachynema (above), some reach diplonema; $0 \%-3 \%$ (depending on the mouse) of the spermatocytes in spreads of Sycp1 $1^{-/-}$testis cell suspensions were in diplonema, compared with $15 \%$ of the spermatocytes in spreads of wild-type testis cell suspensions (late meiotic prophase stages are overrepresented in cell suspensions). Diplotene Sycp1-/- AEs resemble wild-type LEs/AEs, including the thickened ends and the apparent repulsion of the LEs/AEs of homologous chromosomes (Fig. 3T; Supplementary Fig. S2).

Meiotic recombination is initiated in Sycp $1^{-/-}$
spermatocytes, but repair is not completed

$\gamma \mathrm{H} 2 \mathrm{AX}$ is a phosphorylated form of histone variant H2AX, which marks chromatin domains with DNA damage, including DSBs (Rogakou et al. 1999). $\gamma \mathrm{H} 2 \mathrm{AX}$ appeared throughout Sycp $1^{-/-}$preleptotene and leptotene nuclei (Fig. 4F), as in wild type (Fig. 4A; Mahadevaiah et al. 2001). However, whereas $\gamma \mathrm{H} 2 \mathrm{AX}$ becomes largely restricted to asynapsed portions of wild-type zygotene chromosomes (Fig. 4B; Mahadevaiah et al. 2001), it occurs all along the AEs, including the aligned por-

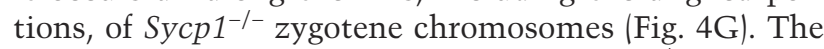
intensity of $\gamma \mathrm{H} 2 \mathrm{AX}$ labeling along the Sycp $1^{-1-}$ bivalents varied somewhat, but in most zygotene cells we could not distinguish separate $\gamma \mathrm{H} 2 \mathrm{AX}$-positive domains (Figs. 4G, 5N). This pattern changed in Sycp1-/- pachynema: Some Sycp $1^{-/-}$pachytene cells displayed a mixture of long stretches of $\gamma \mathrm{H} 2 \mathrm{AX}$ and narrow, intense $\gamma \mathrm{H} 2 \mathrm{AX}$ positive domains, and other pachytene cells (presumably of a later stage) showed only narrow, $\gamma \mathrm{H} 2 \mathrm{AX}$-positive domains along otherwise $\gamma \mathrm{H} 2 \mathrm{AX}$-negative bivalents (Fig. 4H). Diplotene Sycp1 $1^{-/-}$spermatocytes displayed only the latter pattern (Fig. 4I). Late pachytene/early diplotene Sycp $1^{-/-}$spermatocytes contained $110 \pm 4.6$ distinct, narrow $\gamma \mathrm{H} 2 \mathrm{AX}$-positive domains per cell. In earlier spermatocyte stages the $\gamma \mathrm{H} 2 \mathrm{AX}$-positive domains were too indistinct and heterogeneous to be counted. In wild type, we found only distinct, narrow $\gamma \mathrm{H} 2 \mathrm{AX}$-positive domains along synapsed stretches in late zygonema and early pachynema (Fig. 4B,C), and these domains were weakly labeled and disappeared during the course of pachynema (Fig. 4D; Mahadevaiah et al. 2001). Taken together, the $\gamma \mathrm{H} 2 \mathrm{AX}$ pattern suggests that meiotic DSBs are formed in Sycp 1/- meiosis, but that at least some DSBs are not repaired, or their repair gets stuck at some intermediate step that is still marked by $\gamma \mathrm{H} 2 \mathrm{AX}$. Another abnormality in the $\gamma \mathrm{H} 2 \mathrm{AX}$ pattern was found on the sex chromosomes: Wild-type pachytene and diplotene spermatocytes have $\gamma \mathrm{H} 2 \mathrm{AX}$ throughout the chromatin of the XY body (Fig. 4C-E; Mahadevaiah et al. 2001) (a condensed chromatin structure containing the sex chromosomes formed during male meiotic prophase in mammals). In striking contrast, the sex chromosomes of Sycp1-/pachytene and diplotene spermatocytes displayed similar narrow $\gamma \mathrm{H} 2 \mathrm{AX}$-positive domains as the autosomes (Fig. 4H,I).

We also analyzed the putative $\mathrm{H} 2 \mathrm{AX}$ phosphorylating kinase ATR (Turner et al. 2004). In leptonema of wildtype mouse, ATR forms foci in association with AE segments (Fig. 4J), and in early zygonema, ATR foci occur along synapsed and asynapsed portions of LEs/AEs (Fig. $4 \mathrm{~K})$. From mid-zygonema to early pachynema, ATR dis- 

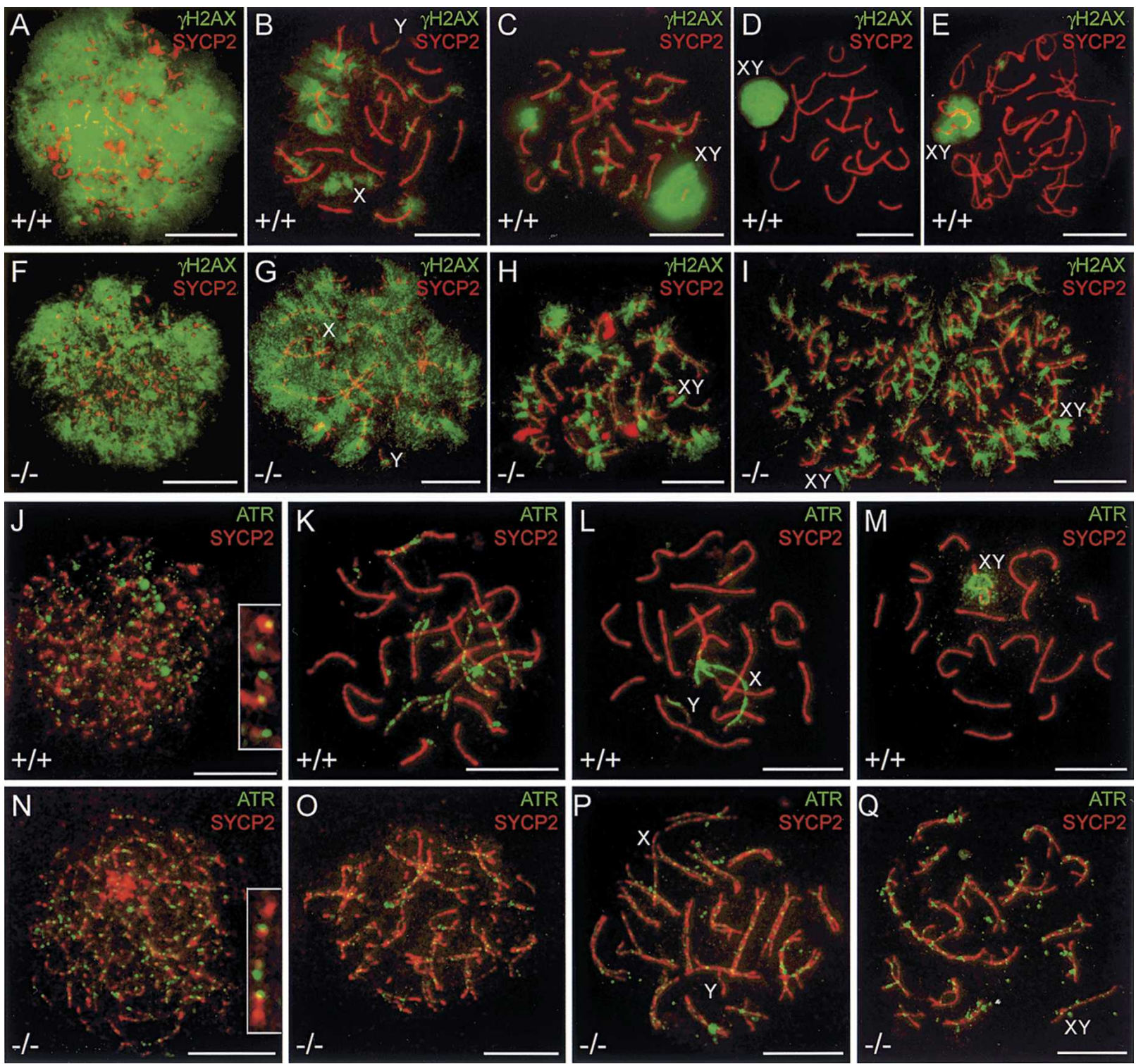

Figure 4. $\gamma \mathrm{H} 2 \mathrm{AX}$ and ATR in wild-type $(+/+)$ and Sycp1-/- $(-/-)$ spermatocytes. $(A-I) \gamma \mathrm{H} 2 \mathrm{AX}$. $(A, F)$ Leptonema. $(B, G)$ Zygonema. $(C)$ Early pachynema. $(D, H)$ Mid-pachynema. $(E, I)$ Diplonema. The sex chromosomes $(X Y)$ form an XY body in wild-type spermatocytes $(C-E)$, but not in Sycp $1^{-1-}$ spermatocytes, even though the $\mathrm{X}$ and $\mathrm{Y}$ chromosomes are associated in the cells in $H$ and $I .(J-Q)$ ATR. (J,N) Leptonema. $(K, O)$ Zygonema. $(L)$ Early pachynema. $(M, P)$ Mid-pachynema. (Q) Diplonema. ATR is present throughout the chromatin of the XY bivalent in wild-type spermatocytes $(M)$, but forms foci and distinct domains along the X and Y chromosomes in Sycp $1^{-1}$ cells $(P, Q)$. Insets in $J$ and $N$ show the close association of ATR with the ends of AE fragments in wild-type $(+/+)$ and Sycp $1^{-/-}$ leptonema. Bars, $10 \mu \mathrm{m}$.

appears from synapsed portions of SCs and accumulates along the nonautosomal parts of the XY bivalent and late pairing ("laggard") portions of autosomal LEs/AEs (Fig. 4L; Turner et al. 2004 and references therein). In Sycp $1^{-1-}$ leptonema and early zygonema, the ATR pattern was indistinguishable from wild type (Fig. 4N). However, whereas the ATR signals disappeared from the synapsed portions of AEs in wild type, they were present along the aligned AEs in Sycp1 $1^{-/-}$spermatocytes, usually in AEasociated foci, or incidentally in distinct domains that were reminiscent of the $\gamma \mathrm{H} 2 \mathrm{AX}$ domains (Fig. 4P,Q). The dense ATR coating of laggard asynapsed portions of AEs as is found in wild type (Fig. $4 \mathrm{~L}$ ) was not found in Sycp1 $1^{-/}$spermatocytes. Strikingly, ATR shows the same aberrant pattern on the $\mathrm{X}$ and $\mathrm{Y}$ chromosome in Sycp $1^{-/-}$pachynema as $\gamma \mathrm{H} 2 \mathrm{AX}$ : It forms few, discrete foci, or occasionally domains, on the AEs of the $\mathrm{X}$ and $\mathrm{Y}$ chromosome rather than covering all non-pseudo-autosomal parts of the AEs of the sex chromosomes (Fig.

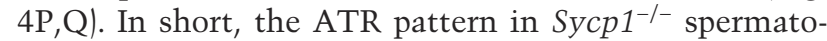
cytes differs in various respects from that in wild type, but the similarity of the ATR and $\gamma \mathrm{H} 2 \mathrm{AX}$ patterns found in wild type (Turner et al. 2004) is also found in Sycp $1^{-/-}$ spermatocytes (Fig. 4). 

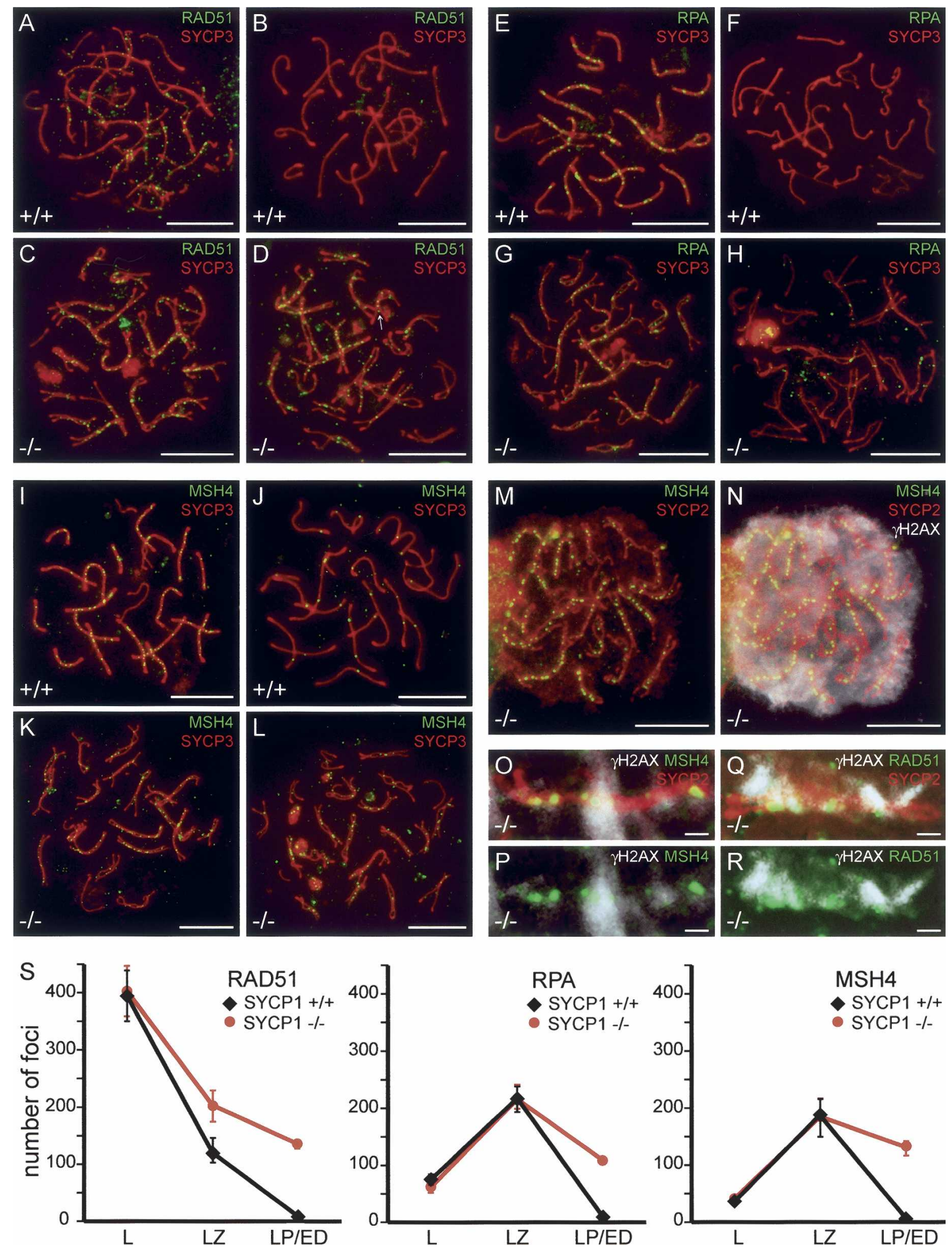

(Figure 5 legend on facing page.) 
Sycp $1^{-/-}$spermatocytes barely form crossovers

To find out which step in meiotic recombination could be blocked in $S y \mathrm{cp}^{-/-}$, we analyzed proteins involved in later steps of meiotic recombination. Rad51 and Dmc1 are RecA homologs required for heteroduplex formation in meiosis, probably by assembling on $3^{\prime}$ tails of resected DSB ends and initiating the strand invasion step (for review, see Shinohara and Shinohara 2004). In wild-type mouse, RAD51/DMC1 foci are formed along the AEs from leptonema on. In zygonema, they are located along synapsed and asynapsed portions of SCs, and in pachynema they gradually disappear (Fig. 5A,B; Ashley and Plug 1998). In Sycp1-/- leptonema, RAD51/DMC1 foci appeared in similar numbers as in wild type, but their number decreased more slowly (Fig. 5C,S; Supplementary Fig. S4). Even late pachytene/early diplotene Sycp $1^{-1-}$ spermatocytes displayed appreciable numbers of RAD51/DMC1 foci (Fig. 5D,S). Thirty percent to $50 \%$ of the RAD51/DMC1 foci were between the aligned AEs in $S y c p 1^{-/-}$late zygonema and late pachynema/early diplonema (Fig. 5D; Supplementary Fig. S4). RAD51/DMC1 foci between aligned AEs occur also in wild-type mouse, maize, and Sordaria (for review, see Zickler and Kleckner 1999; Tessé et al. 2003). Because homolog alignment requires DSBs (Tessé et al. 2003), the RAD51/DMC1 foci between aligned AEs might mark recombinational interactions between homologs. Part of the RAD51/DMC1 foci in Sycp $1^{-/-}$pachytene cells colocalize with $\gamma \mathrm{H} 2 \mathrm{AX}$ domains (Fig. 5Q,R).

RPA binds to single-stranded DNA, and in vitro it enhances nucleoprotein formation by RAD51 if added to the reaction mixture after RAD51 (Pâques and Haber 1999|. In wild-type spermatocytes, RPA foci appear and disappear on average later than RAD51/DMC1 foci (Fig. 5E,F,S; Supplementary Fig. S4; Moens et al. 2002). In Sycp $1^{-1-}$ leptotene and late zygotene spermatocytes, the number of RPA foci and their time of appearance in relation to alignment/synapsis were similar as in wild-type zygonema (Fig. 5G,S; Supplementary Fig. S4). However, Sycp $1^{-1-}$ diplotene spermatocytes still have appreciable numbers of RPA foci (Fig. 5H,S; Supplementary Fig. S4). About $80 \%$ of the RPA foci were located between two aligned AEs of Sycp1 ${ }^{-/-}$spermatocytes (Fig. 5G; Supplementary Fig. S4). RPA foci between aligned AEs occur also in wild-type zygonema (Fig. 5G) and between homologously aligned but not synapsed LE/AE segments between translocation breakpoints in $S y c p 1^{+/+}$pachynema (Plug et al. 1997).
Msh4 is a MutS homolog, which forms a heterodimeric complex with another MutS homolog, Msh5. The Msh4/Msh5 heterodimer probably recognizes and stabilizes meiotic recombination intermediates (Ross-Macdonald and Roeder 1994; Snowden et al. 2004). Yeast Msh4 localizes to sites of synapsis initiation. msh4 mutants show partial and delayed synapsis and $30 \%-50 \%$ of the wild-type level of crossing over, and msh4 mutations affect the same subset of crossovers as zip1 mutations (Novak et al. 2001). In mouse, MSH4 foci colocalize extensively with RPA foci, but appear and disappear slightly later (Moens et al. 2002). Otherwise than in yeast, the number of MSH4 foci in mouse far exceeds the number of chiasmata that will be formed (Fig. 5I,S; Supplementary Fig. S4). Neyton et al. (2004) proposed that in mouse meiosis, MSH4 cooperates first in zygonema with RAD51/DMC1 in homolog alignment, synapsis initiation, and/or in resolution of early DNA-DNA interactions, and subsequently, in pachynema, with MLH1 and MLH3 in crossover formation. In Caenorhabditis, MSH-4 and MSH-5 appear to fulfill only this second role: msh-4 or msh-5 mutants align homologs and assemble SC, but RAD-51 foci persist and crossovers are not formed, which suggests a role for $\mathrm{MSH}-4 / 5$ downstream RAD-51 in crossover formation in Caenorhabditis (Colaiácovo et al. 2003). In mouse, Sycp $1^{-/-}$leptotene and zygotene spermatocytes display similar numbers of MSH4 foci as wild-type spermatocytes (Fig. 5K,M,S; Supplementary Fig. S4). Most Sycp $1^{-1-}$ MSH4 foci are between aligned AEs, indicating that they mark DNA interactions between homologs. However, in Sycp $1^{-/-}$ late pachynema/early diplonema, the number of MSH4 foci is still $70 \%$ of that in late zygonema (Fig. $5 \mathrm{~L}, \mathrm{~S}$; Supplementary Fig. S4). This might suggest that the DNA-DNA interactions to which MSH4 binds are formed normally in Sycp $1^{-/-}$, but that most of these cannot be processed.

MLH1 is essential for crossover formation, both in mammals and yeast (Baker et al. 1996; Hunter and Borts 1997). In mouse, MLH1 foci appear in mid-pachynema, and their position and number closely correlate with those of chiasmata (Froenicke et al. 2002). MLH3 foci largely colocalize with MLH1 foci in the mouse (Svetlanov and Cohen 2004), and MLH3 most probably cooperates with MLH1 in crossover formation (Wang et al. 1999; Lipkin et al. 2002). Sycp $1^{-/-}$spermatocytes do not form MLH1 and MLH3 foci (Fig. 6), which indicates that SYCP1 is required for crossover formation. Accordingly, we observed only univalents in the two natural meta-

Figure 5. Recombination-related proteins along AEs and SCs in wild-type $(+/+)$ and $S y c p 1^{-/-}(-/-)$spermatocytes. $(A-D)$ RAD51/ DMC1. $(A, C)$ Late zygonema. $(B, D)$ Late pachynema. $(E-H)$ RPA. $(E, G)$ Late zygonema. $(F, H)$ Diplonema. $(I-L)$ MSH4. $(I, K)$ Late zygonema. (J) Mid-pachynema. $(L)$ Diplonema. $(M, N)$ MSH4/SYCP2/ $\gamma H 2 A X$ triple labeling of a zygotene Sycp $1^{-/-}$spermatocyte; the number and localization of MSH4 foci appears normal, but the persistence of $\gamma \mathrm{H} 2 \mathrm{AX}$ throughout the chromatin is abnormal. $(O, P)$ $\mathrm{MSH} 4 / \mathrm{SYCP} 3 / \gamma \mathrm{H} 2 \mathrm{AX}$ triple labeling of a late pachytene Sycp $1^{-/-}$bivalent, to show that part of the $\gamma \mathrm{H} 2 \mathrm{AX}$ domains colocalize with an MSH4 focus. $(Q, R)$ RAD51/SYCP2/ $\gamma \mathrm{H} 2 \mathrm{AX}$ triple labeling of a late pachytene Sycp $1^{-1-}$ bivalent, to show that part of the $\gamma \mathrm{H} 2 \mathrm{AX}$ domains colocalize with a RAD51 focus. (S) Counts of RAD51, RPA, and MSH4 foci in successive stages of meiotic prophase; the vertical axes represent the number of $\mathrm{AE}$ or SC associated foci per cell; the vertical bars represent the observed range of the number of foci per cell in a given spermatocyte stage. For more details of the counts, see Supplementary Figure S4. Bars: $A-N, 10 \mu \mathrm{m} ; \mathrm{O}-R$, $1 \mu \mathrm{m}$. 

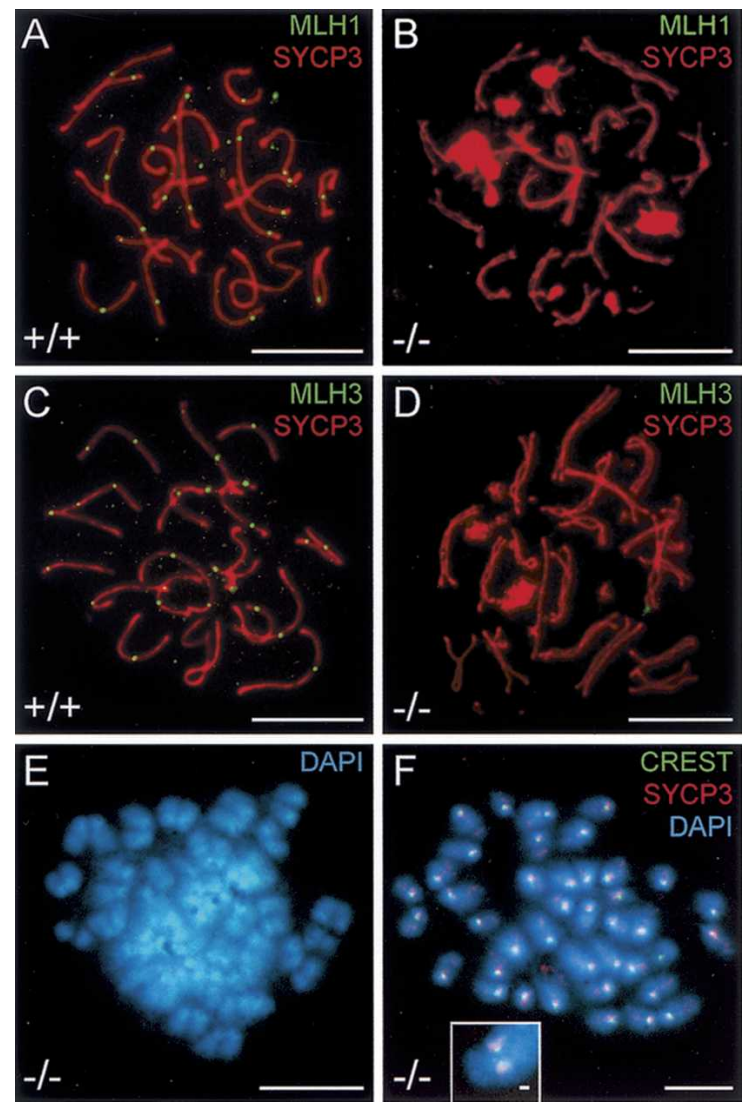

Figure 6. Formation of crossovers and chiasmata. MLH1 labeling $(A, B)$ and MLH3 labeling $(C, D)$ of wild-type $(+/+)$ or Sycp $1^{-/-}$ $(-/-)$ pachytene spermatocytes. The Sycp $1^{-/-}$spermatocytes do not assemble MLH1 or MLH3 foci. $(E, F)$ A natural $(E)$ and an OA-induced $(F)$ metaphase I spermatocyte of $S y c p 1^{-1-}$. In the cells shown here, only univalents can be identified; the inset in $F$ shows a bivalent found in another OA-induced Sycp1 $1^{-/-}$metaphase I. Bars: $A-F, 10 \mu \mathrm{m}$; inset in $F, 1 \mu \mathrm{m}$.

phases I that we found among spread spermatocytes of Sycp $1^{-1-}$ mice (Fig. 6E). If we forced pachytene or diplotene Sycp1 $1^{-/}$spermatocytes to condense their chromosomes, using okadaic acid (OA), most chromosomes formed univalents (Fig. 6F). Chromosomal fragments were rare in natural metaphase I or OA-induced metaphase I-like configurations of Sycp 1 ${ }^{-1-}$ (Fig. 6E,F).

Taken together, the immunofluorescence labeling of foci suggests that $S y c p 1^{-/-}$spermatocytes can initiate meiotic recombination at wild-type level and establish stable homologous alignment of autosomes. However, many repair/recombination intermediates are not repaired and crossovers are not formed.

\section{Sycp $1^{-/}$spermatocytes do not form XY bodies}

In $28 \%$ of the Sycp $1^{-/-}$pachytene spermatocytes, the $\mathrm{X}$ and $\mathrm{Y}$ chromosome were associated, but this did not ensure formation of an XY body. In Sycp1 $1^{-/-}$pachynema, $\gamma \mathrm{H} 2 \mathrm{AX}$ and ATR occurred in a similar discrete pattern along the AEs of the XY bivalent as along autosomal AEs
(Fig. 4I,P,R) (rather than covering the nonautosomal parts of the sex chromosomes), the characteristic DAPIintense domain of the XY body was not formed, and the AEs of the $\mathrm{X}$ and $\mathrm{Y}$ chromosomes were not curled or bent, as is usually seen in wild-type $\mathrm{XY}$ bodies (Fig. 4, cf. $\mathrm{D}, \mathrm{E}$ and $\mathrm{H}, \mathrm{I}, \mathrm{Q})$. We will analyze the $\mathrm{XY}$ bivalent in Sycp $1^{-/}$spermatocytes in more detail in a separate study.

\section{Discussion}

In this study we disrupted the mouse SYCP1 gene and analyzed the effect on meiotic recombination and chromosome behavior by an immunocytochemical approach. We will assume that immunofluorescence signals represent functional protein complexes and that orthologous proteins fulfill similar roles in mouse and yeast meiosis, unless there are indications that this is not so. In addition, we will have to make assumptions when and how the proteins act that we detect by immunofluorescence, to link the cytological observations in Sycp1 ${ }^{-/-}$mice to studies at the DNA and cytological level in other organisms.

\section{Early meiosis in Sycp1 $1^{-/-}$spermatocytes}

We used AE morphology as detected by SYCP2 or SYCP3 labeling and alignment/synapsis as a basis for staging (Fig. 3; Supplementary Fig. S3). Sycp $1^{-/-}$and wild-type spermatocyte stages that correspond by these criteria also show similar patterns of cohesins (shown for REC8 in Fig. 3K-T), but display largely different patterns of recombination-related proteins other than cohesins. Leptonema is the only analyzed stage in which Sycp $1^{-/-}$and wild-type spermatocytes show similar immunofluorescence patterns of all analyzed proteins: The $\gamma \mathrm{H} 2 \mathrm{AX}$ and ATR patterns are similar, and RAD51/DMC1, RPA, and MSH4 foci occur in similar numbers in wild-type and Sycp $1^{-/-}$leptonema, indicating that DSBs are induced and that some post-DSB step(s), presumably at least resection of DSB ends (Xu et al. 1997), take place at wildtype levels in Sycp $1^{-/-}$leptonema. However, differences (other than synapsis) between Sycp $1^{-/-}$and wild type become apparent between leptonema and zygonema, in particular with respect to $\gamma \mathrm{H} 2 \mathrm{AX}$ and ATR (Fig. 4K). Furthermore, the number of RAD51/DMC1 foci has decreased between leptonema and zygonema, but less so in Sycp $1^{-/-}$than in wild type (Fig. 5S; Supplementary Fig. S4). The numbers of RPA and MSH4 foci on the other hand are similar in late zygonema in mutant and wild type (Fig. 5S; Supplementary Fig. S4). In wild type, RPA and MSH4 foci most likely arise from RAD51/DMC1 foci, and then lose RAD51/DMC1 (Moens et al. 2002). Although the RAD51/DMC1 foci occur in similar numbers per cell as MSH4 and RPA foci in Sycp1 $1^{-/-}$late zygonema (Fig. 5S), they cannot completely overlap with these foci, because $>80 \%$ of the MSH 4 and RPA foci are between the aligned AEs, but only $46 \%$ of the RAD51/ DMC1 foci (Supplementary Fig. S4). Possibly MSH4 foci 
are normal in Sycp1-/- late zygonema, but some repair pathway is affected that is marked by RAD51/DMC1 but not by MSH4 foci. However, as the turnover of MSH4 and RAD51/DMC1 foci is not known, other explanations are conceivable.

Important questions about the immunofluorescence signals in zygonema are, What does the $\gamma \mathrm{H} 2 \mathrm{AX}$ signal throughout the Sycp1 $1^{-/-}$nuclei indicate? And what do the MSH4 foci represent? In yeast, the number of Msh4 foci per cell roughly equals the number of Zip1-dependent crossovers per cell (Novak et al. 2001), and it seems likely that most or all MSH4 foci in yeast mark sites of future crossovers. In mammals and Arabidopsis, the number of MSH4 foci exceeds the number of crossovers by far, so in these organisms most MSH4 foci will not become crossovers, but mark possibly recombinational interactions that serve homolog alignment (Higgins et al. 2004; Neyton et al. 2004); the MSH4 images of late zygotene cells (Fig. 5K,M; Supplementary Fig. S4) suggest that such interactions occur normally in $S y c p 1^{-/-}$. An ensuing question is whether there are any crossover-designated MSH4 foci at all among the MSH4 foci in mouse zygonema. In wild-type mouse this might be the case, because some MSH4 foci colocalize with MLH1 in pachynema (Santucci et al. 2000), but the question remains whether these colocalizing MSH4 foci were already present in zygonema. Based on work in yeast (Börner et al. 2004) we would expect so. If so, then they would comprise $<10 \%$ of all late zygotene MSH4 foci in wild type. It would probably have escaped us if Sycp1-/would lack this type of MSH4 foci (if any) in zygonema. So we do not know whether crossover-designated MSH4 foci are missing from $S y c p 1^{-/-}$zygotene spermatocytes (either because crossovers are not designated, or because crossover-designated intermediates fail to form MSH4 foci), or whether crossover-designated MSH4 foci are assembled in Sycp $1^{-/-}$zygonema, but fail to become crossovers in a later stage.

Similar questions arise with respect to $\gamma \mathrm{H} 2 \mathrm{AX}$. $\gamma \mathrm{H} 2 \mathrm{AX}$ is not restricted to AEs, but occurs throughout chromatin loops. Possibly, a single meiotic DSB causes $\mathrm{H} 2 \mathrm{AX}$ phosphorylation on megabases of DNA /which corresponds to tens of loops), like DSBs in somatic cells (Rogakou et al. 1999). Therefore $\gamma \mathrm{H} 2 \mathrm{AX}$-positive domains might contain only one or a few DSBs (or other $\gamma \mathrm{H} 2 \mathrm{AX}$-marked recombination intermediates) associated with the AEs (Fig. 5O-R), but do not necessarily also have DSBs in the loops. However, even if we assume this, it is not clear which lesions $\gamma \mathrm{H} 2 \mathrm{AX}$ might mark in Sycp $1^{-/-}$zygonema. Late zygotene spermatocytes of wild type and Sycp $1^{-1-}$ have similar numbers of RPA and MSH4 foci (Fig. 5S; Supplementary Fig. S4), yet $\gamma \mathrm{H} 2 \mathrm{AX}$ is restricted to asynapsed AEs and some weak domains in synapsed SC segments in wild type (Fig. 4B), but covers all the chromatin in Sycp $1^{-/-}$(Figs. 4C, 5M). Possible explanations for this difference are (1) MSH4, RPA, and/ or RAD51/DMC1 foci in wild type and Sycp1-/- look similar but contain different recombination intermediates; only those present in $S y c p 1^{-/-}$are marked by $\gamma \mathrm{H} 2 \mathrm{AX}$. (2) The 70\% "extra" RAD51/DMC1 foci in
Sycp $1^{-/-}$late zygonema (Fig. 5S) bring about the overall $\gamma \mathrm{H} 2 \mathrm{AX}$ labeling. We doubt whether this relatively small number of RAD51/DMC1 marked DSBs or recombination intermediates (60-70 per cell) could cause this. (3) Late zygotene Sycp $1^{-/-}$spermatocytes contain, besides the RAD51/DMC1, RPA, and MSH4 marked DNA structures, other DNA lesions that are not marked by any of these proteins, but are marked by $\gamma \mathrm{H} 2 \mathrm{AX}$, e.g., unresected DSBs. This seems unlikely: If yeast zip1 mutants are similar to $S y c p 1^{-/-}$in this respect, it would predict an elevated level of that type of DNA-lesions in zip1; there are no indications for this (Börner et al. 2004). (4) The $\gamma \mathrm{H} 2 \mathrm{AX}$ labeling in late zygotene Sycp $1^{-/-}$spermatocytes reflects some disorganization in the $S y c p 1^{-/-}$cell that is not related to the presence of DSBs. (5) Loss of DSBs or recombination intermediates (due to repair) is uncoupled from loss of $\gamma \mathrm{H} 2 \mathrm{AX}$ staining in Sycp $1^{-/-}$. This may result in the persistence of $\gamma \mathrm{H} 2 \mathrm{AX}$ labeling at sites where there are no breaks (anymore). Although there are no conclusive arguments against the other possible explanations, we prefer the last one, because it accounts for the close correlation between asynapsis and the presence of $\gamma \mathrm{H} 2 \mathrm{AX}$ in wild type. A similar correlation exists between asynapsis and the presence of ATR (Turner et al. 2004) and RAD50 and MRE11 (Eijpe et al. 2000). This correlation could either mean that synapsis can only occur in chromosomal regions where these proteins have been lost, or that these proteins are lost from chromatin loops upon synapsis (or some local SYCP1-dependent event preceding synapsis). The presence of $\gamma \mathrm{H} 2 \mathrm{AX}$ all over the chromatin in Sycp1 $1^{-/-}$zygotene nuclei argues for the second interpretation: Perhaps synapsis/SYCP1 causes first the loss of ATR, which is then followed by loss of $\gamma \mathrm{H} 2 \mathrm{AX}$. In Sycp $1^{-/-}$mid- to late pachynema, most $\gamma \mathrm{H} 2 \mathrm{AX}$ eventually disappears from the chromatin, except from a number of distinct domains (Fig. 4H). Since most of these domains have RAD51/DMC1 (Fig. 5Q,R) or MSH4 (Fig. 5O,P) foci at their bases, they probably represent loops in which repair has not been completed.

\section{Role of SYCP1 in later steps of meiotic recombination}

In wild-type late pachynema/early diplonema, most or all RAD51/DMC1, RPA, and MSH4 foci have disappeared, whereas $S y c p 1^{-/-}$late pachytene/early diplotene cells still have $50 \%-70 \%$ of the number of foci found in zygonema (Fig. 5S; Supplementary Fig. S4). Similar observations have been made in TF mutants of Caenorhabditis (Alpi et al. 2003; Colaiácovo et al. 2003) and yeast (Novak et al. 2001). Apparently meiotic recombination is blocked or impeded at a step where these proteins act, possibly single end invasion, because yeast Rad51 and Dmc1 are required for strand invasion (Hunter and Kleckner 2001). Thirty percent to $50 \%$ of the RAD51/ DMC1, RPA, and MSH4 foci disappear between zygonema and late pachynema/diplonema of $S y c p 1^{-/-}$. Whether these foci represent a specific subpopulation or a random sample of the foci in late zygonema is not clear.

Mouse Sycp1 $1^{-/-}$mutants have in common with TF 
mutants in other species that crossover formation is affected. More than $90 \%$ of the crossovers in the mouse depend on synapsis/SYCP1 (Fig. 6E,F). However, the number of RAD51/DMC1, RPA, and MSH4 foci and $\gamma \mathrm{H} 2 \mathrm{AX}$ signals that are still present in $S y c p 1^{-/-}$diplonema exceeds the number of crossovers in wild type about fivefold: We counted $117 \pm 17 \mathrm{MSH} 4$ foci per diplotene Sycp $1^{-/-}$spermatocyte, whereas there are on average 21-25 exchanges per cell in male mouse meiosis (Koehler et al. 2002). SYCP1 is therefore not only required for crossover formation, but also for repair of DSBs that will not become crossovers, at least if persisting MSH4 foci in Sycp $1^{-/-}$still mark DNA lesions. Upon exposure to OA, Sycp1 $1^{-/-}$spermatocytes repair the recombination intermediates (if any) that underlie the RAD51/DMC1, RPA, and MSH4 foci, because chromatid breaks are rare in OA-induced metaphases I (Fig. 6F). Possibly, OA opens up a DNA repair pathway that is not normally used in wild type, for instance, by releasing the sister chromatid as template for repair. However, exposure to OA reveals little or no crossing over in $S y c p 1^{-/-}$, whereas it reveals crossover formation in wild type. Therefore, SYCP1 must have a role in crossover formation besides its proposed role in the repair of breaks that will not become crossovers.

To summarize the role of SYCP1 in recombination: A substantial fraction of meiotic DSBs does not require SYCP1 for repair (Fig. 5S); it is not known whether these breaks are a random sample or a specific subset of breaks. One hundred to 200 breaks per cell (as estimated from the number of foci and $\gamma \mathrm{H} 2 \mathrm{AX}$ signals in late pachynema) require SYCP1 and/or synapsis for repair. And the formation of $>90 \%$ of the crossovers depends on SYCP1 and/or synapsis. This resembles the yeast zip1 phenotype. The role of SYCP1 in crossover formation is a conserved TF function in all species analyzed thus far. Possibly SYCP1/the SC serve as support for the assembly of MLH1 foci and/or enhance crossing over by providing a close apposition of homologs. Alternatively, or in addition, TF proteins/synapsis might ensure certain overall structural alterations in the bivalents that lead to crossover formation (Börner et al. 2004).

\section{Role of SYCP1 in XY body formation}

This study revealed an unexpected role of SYCP1 in the formation of the XY body. Turner et al. (2004) presented recently evidence that coating of asynapsed portions of AEs with BRCA1 and ATR was correlated with H2AX phosphorylation and transcriptional inactivation. In the $\mathrm{XY}$ bivalent this would ultimately result in the formation of an XY body. The aberrant distribution of ATR and $\gamma \mathrm{H} 2 \mathrm{AX}$ in Sycp $1^{-/-}$pachytene spermatocytes provides therefore an obvious explanation for the failure to form $\mathrm{XY}$ bodies. However, the question remains why ATR is distributed aberrantly. Perhaps ATR relocates to asynapsed portions of AEs after it has disappeared from synapsed portions of AEs; this might explain the dense coating (rather than discrete foci) of ATR along the last asynapsed portions of AEs, including those of the sex chromosomes. Possibly ATR does not relocate in Sycp $1^{-/}$ -, because it is sequestered at unrepaired DNA breaks, and/or because SYCP1/synapsis is directly or indirectly required for relocation of ATR.

\section{Comparison with other meiotic recombination-deficient mouse mutants}

Besides Sycp1, other mouse genes homologous to yeast genes involved in the Zip1-dependent pathway of crossover formation have been knocked out, namely, Msh4 (Kneitz et al. 2000), Msh5 (de Vries et al. 1999; Edelmann et al. 1999), and Dmc1 (Pittman et al. 1998; Yoshida et al. 1998). Contrary to Sycp $1^{-/-}$mice, these knockouts display partial and nonhomologous alignment/synapsis rather than full-length homologous alignment. Presumably, MSH4, MSH5, and DMC1 are indispensable for establishment of stable recombinational interactions between homologs in the mouse, whereas SYCP1 contributes only to a minor extent to the stability of such interactions, at least in leptonema till pachynema. Msh4, Msh5, and perhaps Dmc1 knockouts enter apoptosis when the spermatogenic epithelium is in developmental stage IV and the spermatocytes should be in early/mid-pachynema (de Vries et al. 1999; de Rooij and de Boer 2003). At least a small proportion of Sycp1 $1^{-/-}$ spermatocytes progresses further and reaches diplonema or exceptionally metaphase I. This could be related to the ability of Sycp1 $1^{-/-}$spermatocytes to establish reasonably stable homologous alignment. Among other mutant mice with a less defined but on average later arrest in meiosis than early/mid pachytene (stage IV), there are several that can align or synapse chromosomes homologously, including Mlh1, Mlh3, and Brca1 mutants (for review, see de Rooij and de Boer 2003).

\section{Materials and methods}

\section{Construction of the targeting vector}

To inactivate the Sycp1 gene, we designed a targeting construct to replace exons $2-8$ by a neomycin gene, using pKO Scrambler V905 as a vector (Lexicon Genetics, Incorporated). The neomycin phosphotransferase gene was isolated as an AscI fragment from pKO Select Neo (Lexicon Genetics) and inserted at the unique AscI site of pKO V905. The thymidine kinase gene was derived from pKO Select TK (Lexicon Genetics) by RsiII digestion and subcloned at the unique RsiII site of pKO V905. Genomic fragments were isolated after screening of a $\lambda$ FixII library derived from 129/Ola E14 cells (a gift of B. Vennström, Mouse Camp Transgene Facility, Karolinska Institute, Stockholm, Sweden). A 2.4-kb SalI (vector derived)-SacII fragment was used as a left arm. This fragment was first cloned in pGEM-T Easy (Promega), excised as a SalI-NotI fragment, and cloned as a blunt fragment on the HpaI site of pKO V905. A 6-kb EcoRI fragment was used as the right arm and inserted in the EcoRI site of the targeting vector (Fig. 1). The final pKO plasmid mentioned above, containing all four elements, was linearized with Sall before electroporation.

Targeted inactivation of the Sycp1 gene

129/Ola-derived IB10 ES cells (a subclone from E14 ES cells) were cultured on lethally irradiated mouse embryonic fibro- 
blasts in Dulbecco's modified Eagle's medium supplemented with $10 \%$ fetal calf serum (Biocell Laboratories Inc.), $2 \mathrm{mM}$ L-glutamate, $1 \mathrm{mM}$ sodium pyruvate, nonessential amino acids, $0.1 \mathrm{mM} \beta$-mercaptoethanol, $10^{3} \mathrm{U} / \mathrm{mL}$ leukemia inhibitory factor (LIF), penicillin $(100 \mathrm{U} / \mathrm{l})$ and streptomycin $(100 \mu \mathrm{g} / \mathrm{L})$. $4 \times 10^{7}$ ES cells were resuspended in $300 \mu \mathrm{L}$ PBS, containing 65 $\mu \mathrm{g}$ linearized targeting vector and electroporated at $800 \mathrm{~V}$ and a capacitance of $3 \mu \mathrm{F}$. Cells were seeded in five $9-\mathrm{cm}$ dishes and after 24 and $72 \mathrm{~h} \mathrm{G} 418(175 \mu \mathrm{g} / \mathrm{mL})$ and gancyclovir $(1.3 \mu \mathrm{g} / \mathrm{mL})$ were added, respectively. Resistant colonies were isolated after $10 \mathrm{~d}$ of selection and expanded and genomic DNA was analyzed by PCR and blot hybridization. The sequences of the upstream and downstream primers FW4 and neoFW3 are $5^{\prime}$-GGATTG CACGCAGGTTCTCC-3' and 5'-CATACATGCCACGGAGG AAG-3', respectively. Amplifications were performed using the Expand High Fidelity PCR system according to the manufacturer's instructions (Roche Applied Science). Primers were annealed at $60^{\circ} \mathrm{C}$. Correct targeting results in a $3.8-\mathrm{kb}$ PCR fragment, which was confirmed by blot hybridization. We microinjected targeted ES cells into C57BL/6 blastocysts to generate chimeras, and chimeric males were mated with $\mathrm{C} 57 \mathrm{BL} / 6 \mathrm{fe}-$ males. To produce Sycp $1^{-/-}$mice, we intercrossed heterozygous offspring. We genotyped mice by PCR on tail DNA using the primers scp40 (5'-CATGCTCGAACAGGTTAGTA-3'), scp41 (5'-GTGACAACTGCCAGAATTAG-3'), neo7 (5'-CATACGC TTGATCCGGCTC $\left.-3^{\prime}\right)$, and neo9 (5'-GATGGCTGGCAACTA GAAGG-3'). Scp40 and scp41 give a 382-bp fragment diagnostic of the wild-type Sycp1 allele, while neo7 and neo9 give a 488-bp fragment diagnostic of the neomycin selectable marker. PCR conditions were $1 \mathrm{~min}$ at $93^{\circ} \mathrm{C}, 1 \mathrm{~min}$ at $55^{\circ} \mathrm{C}$, and $2 \mathrm{~min}$ at $72^{\circ} \mathrm{C}$ for 35 cycles.

\section{Western blot analysis}

We prepared cell suspensions from testes of $S y c p 1^{-/-}$and Sycp $1^{+/-}$mice (Heyting and Dietrich 1991) and lysed the cells in Laemmli sample buffer. We loaded $5 \times 10^{5}$ lysed cells per 0.8$\mathrm{cm}$-wide slot of a $10 \%$ polyacrylamide gel and separated the proteins by sodium dodecyl sulfate-polyacrylamide gel electrophoresis. After transfer of the proteins to nitrocellulose (Schleicher \& Schuel) by electroblotting, we stained the resulting blots with Ponceau S and scanned them using an Agfa Snapscan 1212 flatbed scanner before we probed them with antibodies. From each lane, four strips were cut, which were each incubated in one of the anti-SYCP1 antisera, and then in secondary (antirabbit) antibodies conjugated to alkaline phosphatase (AP; Promega), as described (Offenberg et al. 1998).

\section{Histological analysis and TUNEL assay}

Animals were killed by cervical dislocation. Testes, epididymides, and seminal vesicles, or ovaries and uterus were examined and weighed. From each male, we fixed one testis and epididymis in Bouin's fixative for $24 \mathrm{~h}$ at room temperature, and the other testis in phosphate-buffered formalin for $24 \mathrm{~h}$ at $4^{\circ} \mathrm{C}$. Subsequently, organs were embedded in paraffin. Mounted sections were deparaffinized, rehydrated, and stained with hematoxylin and eosin. For TUNEL analyses, formalin-fixed sections were mounted on glass slides coated with a $2 \%$ solution of 3-aminopropyltriethoxysilane in acetone, deparaffinized, and pretreated with proteinase K (Sigma) and peroxidase (Gavrieli et al. 1992). Slides were subsequently washed in terminal deoxynucleotidyl transferase (TdT) buffer (100 mM cacodylate buffer, $1 \mathrm{mM} \mathrm{CaCl}_{2}, 0.1 \mathrm{mM}$ dithiothreitol at $\mathrm{pH}$ 6.8) for $5 \mathrm{~min}$ (Gorczyca et al. 1993) and incubated for at least $30 \mathrm{~min}$ at $25^{\circ} \mathrm{C}$ in TdT buffer containing $0.01 \mathrm{mM}$ Biotin-16-dUTP (Roche Diag- nostics) and $0.4 \mathrm{U} / \mu \mathrm{L}$ TdT enzyme (Promega). The enzymatic reaction was stopped in TB buffer $(300 \mathrm{mM} \mathrm{NaCl}, 30 \mathrm{mM} \mathrm{Na}$ citrate at $\mathrm{pH}$ 7.0), and the sections were washed (Gavrieli et al. 1992). Slides were then incubated with streptABComplex/ horseradish peroxidase conjugate (Dako) for $30 \mathrm{~min}$ and washed in PBS. dUTP-biotin labeled cells were visualized with 3,3'diaminobenzidine tetrahydrochloride $(\mathrm{DAB}) /$ metal concentrate (Pierce). Then we counterstained the sections with hematoxylin and counted the number of TUNEL-positive cells per crosssectioned tubule. However, for Sycp $1^{-/-}$mice this was not possible, because numerous TUNEL-positive nuclei were clustered in single cross-sectioned tubules. Therefore we counted the number of cross-sectioned tubules with no, one to five, or more than five apoptotic nuclei. Tubules without germ cell development up to meiotic prophase were excluded from the analysis. We performed this analysis on two Sycp $1^{+/-}$and two Sycp $1^{-/-}$ mice, classifying a minimum of 150 tubule sections for each genotype.

Cytology, immunocytochemistry, and chromosome painting

The antibodies used in this study are listed in the Supplemental Material. Paraffin and frozen sections of mouse testis (Meuwissen et al. 1992), and dry-down (Peters et al. 1997) or squash (Page et al. 1998) preparations of testis cell suspensions were prepared, incubated for immunocytochemistry, and analyzed as described (Meuwissen et al. 1992; Eijpe et al. 2003). In some experiments, we exposed the cells to $1.25 \mu \mathrm{M}$ OA for $5 \mathrm{~h}$ (Wiltshire et al. 1995) before spreading. For ultrastructural analysis we prepared uranyl-acetate-stained agar filtrates of lysed spermatocytes and analyzed them as described (Heyting and Dietrich 1991).

\section{Acknowledgments}

We thank C. Beerends, P. de Boer, P. Cohen, M.A. Handel, Ch. Her, R. Jessberger, R. Kanaar, T. de Lange, P. Moens, J.-M. Peters, and M. Volker for antibodies, and B. Vennström for the $\lambda$ FixII library. We are indebted to the Central Mouse Facility at the LUMC for blastocyst injections and general mouse facilities. We thank Jaap Jansen (LUMC) for his advice in culturing ES cells; M. Eijpe, H.H. Offenberg, and A.J.J. Dietrich for help and practical advice; and two anonymous reviewers for several useful suggestions. The Netherlands Society for Scientific Research (NWO) (grant 901-01-097) and the EU (contract QLK3-200000365) financially supported this work.

\section{References}

Alpi, A., Pasierbek, P., Gartner, A., and Loidl, J. 2003. Genetic and cytological characterization of the recombination protein RAD-51 in Caenorhabditis elegans. Chromosoma 112: 6-16.

Anderson, L.K., Offenberg, H.H., Verkuijlen, W.C., and Heyting, C. 1997. RecA-like proteins make part of early meiotic nodules in lily. Proc. Natl. Acad. Sci. 94: 6868-6873.

Ashley, T. 2004. The mouse "tool box" for meiotic studies. Cytogenet. Genome Res. 105: 166-171.

Ashley, T. and Plug, A.W. 1998. Caught in the act: Deducing meiotic function from protein immunolocalization. Curr. Top. Dev. Biol. 37: 201-239.

Baarends, W., Wassenaar, E., Hoogerbrugge, J.W., van Capellen, G., Roest, H.P., Vreeburg, J., Ooms, M., Hoeijmakers, J.H.J., and Grootegoed, J.A. 2003. Loss of HR6B ubiquitin-conjugating activity results in damaged synaptonemal complex structure and increased crossing-over frequency during the male 
meiotic prophase. Mol. Cell. Biol. 23: 1151-1162.

Baker, S.M., Plug, A.W., Prolla, T.A., Bronner, C.E., Harris, A.C., Yao, X., Christie, D.-M., Monell, C., Arnheim, N., Bradley, A., et al. 1996. Involvement of mouse Mlh1 in DNA mismatch repair and meiotic crossing over. Nat. Genet. 13: 336-342.

Börner, G.V., Kleckner, N., and Hunter, N. 2004. Crossover/ noncrossover differentiation, synaptonemal complex formation, and regulatory surveillance at the leptotene/zygotene transition of meiosis. Cell 117: 29-45.

Colaiácovo, M.P., MacQueen, A.J., Martinez, P.E., McDonald, K., Adamo, A., La Volpe, A., and Villeneuve, A.M. 2003. Synaptonemal complex assembly in C. elegans is dispensable for loading strand-exchange proteins but critical for proper completion of recombination. Dev. Cell 5: 463-474.

de Rooij, D.G. and de Boer, P. 2003. Specific arrest in spermatogenesis in genetically modified and mutant mice. Cytogenet. Genome Res. 103: 267-276.

de Vries, S.S., Baart, E.B., Dekker, M., Siezen, A., de-Rooij, D.G., de Boer, P., and te Riele H. 1999. Mouse MutS-like protein Msh5 is required for proper chromosome synapsis in male and female meiosis. Genes \& Dev. 13: 523-531.

Edelmann, W., Cohen, P.E., Kneitz, B., Winand, N., Lia, M., Heyer, J., Kolodner, R., Pollard, J.W., and Kucherlapati, R. 1999. Mammalian MutS homologue 5 is required for chromosome pairing in meiosis. Nat. Genet. 21: 123-127.

Eijpe, M., Offenberg, H., Goedecke, W., and Heyting, C. 2000. Localisation of RAD50 and MRE11 in spermatocyte nuclei of mouse and rat. Chromosoma 109: 123-132.

Eijpe, M., Offenberg, H., Jessberger, R., Revenkova, E., and Heyting, C. 2003. Meiotic cohesin REC8 marks the axial elements of rat synaptonemal complexes before cohesins SMC1 $\beta$ and SMC3. J. Cell Biol. 160: 657-670.

Froenicke, L., Anderson, L.K., Wienberg, J., and Ashley, T. 2002. Male mouse recombination maps for each autosome identified by chromosome painting. Am. J. Hum. Genet. 71: 13531368.

Gavrieli, Y., Herman, Y., and Sasson, S.A. 1992. Identification of programmed cell death in situ via specific labeling of nuclear DNA fragmentation. J. Cell Biol. 119: 493-501.

Gorczyca, W., Gong, J., and Darzynkiewicz, Z. 1993. Detection of DNA strand breaks in individual apoptotic cells by the in situ terminal deoxynucleotidyl transferase and nick translation assays. Cancer Res. 53: 1945-1951.

Heyting, C. and Dietrich, A.J. 1991. Meiotic chromosome preparation and protein labeling. Methods Cell Biol. 35: 177-202.

Higgins, J.D., Armstrong, S.J., Franklin, F.C.H., and Jones, G.H. 2004. The Arabidopsis MutS homolog AtMSH4 functions at an early step in recombination: Evidence for two classes of recombination in Arabidopsis. Genes \& Dev. 18: 2557-2570.

Hunter, N. 2003. Synaptonemal complexities and commonalities. Mol. Cell 12: 533-535.

Hunter, N. and Borts, R.H. 1997. Mlh1 is unique among mismatch repair proteins in its ability to promote crossing over during meiosis. Genes \& Dev. 11: 1573-1582.

Hunter, N. and Kleckner, N. 2001. The single-end invasion. An asymmetric intermediate at the double-strand break to double-Holliday junction transition of meiotic recombination. Cell 106: 59-70.

Jang, J.K., Sherizen, D.E., Bhagat, R., Manheim, E.A., and McKim, K.S. 2003. Relationship between DNA double-strand breaks to synapsis in Drosophila. J. Cell Sci. 116: 3077.

Kneitz, B., Cohen, P.E., Avdievich, E., Zhu, L.Y., Kane, M.F., Hou, H., Kolodner, R.D., Kucherlapati, R., Pollard, J.W., and Edelmann, W. 2000. MutS homolog 4 localization to meiotic chromosomes is required for chromosome pairing during meiosis in male and female mice. Genes \& Dev. 14: 10851097.

Koehler, K.E., Cherry, J.P., Lynn, A., Hunt, P.A., and Hassold, T.J. 2002. Genetic control of mammalian meiotic recombination. I. Variation in exchange frequencies among males from inbred mouse strains. Genetics 162: 297-306.

Lipkin, S.M., Moens, P.B., Wang, V., Lenzi, M., Shanmugarajah, D., Gilgeous, A., Thomas, J., Cheng, J., Touchman, J.W., Green, E.D., et al. 2002. Meiotic arrest and aneuploidy in MLH3-deficient mice. Nat. Genet. 31: 385-390.

MacQueen, A.J., Colaiácovo, M.P., McDonald, K., and Villeneuve, A.M. 2002. Synapsis-dependent and -independent mechanisms stabilize homolog pairing during meiotic prophase in C. elegans. Genes \& Dev. 16: 2428-2442.

Mahadevaiah, S.K., Turner, J.M.A., Baudat, F., Rogakou, E.P., de Boer, P., Blanco-Rodriguez, J., Jasin, M., Keeney, S., Bonner, W.M., and Burgoyne, P.S. 2001. Recombinational DNA double-strand breaks in mice precede synapsis. Nat. Genet. 27: 271-276.

Meuwissen, R.L., Offenberg, H.H., Dietrich, A.J., Riesewijk, A., van Iersel, M., and Heyting, C. 1992. A coiled-coil related protein specific for synapsed regions of meiotic prophase chromosomes. EMBO J. 11: 5091-5100.

Moens, P.B., Kolas, N.K., Tarsounas, M., Marcon, E., Cohen, P.E., and Spyropoulos, B. 2002. The time course and chromosomal localization of recombination-related proteins at meiosis in the mouse are compatible with models that can resolve the early DNA-DNA interactions without reciprocal recombination. J. Cell Sci. 115: 1611-1622.

Neyton, S., Lespinasse, F., Moens, P.B., Paul, R., Gaudray, P., Paquis-Flucklinger, V., and Santucci-Darmanin, S. 2004. Association between MSH4 (MutS homologue 4) and the DNA strand-exchange RAD51 and DMC1 proteins during mammalian meiosis. Mol. Hum. Reprod. 10: 917-924.

Novak, J.E., Ross-Macdonald, P.B., and Roeder, G.S. 2001. The budding yeast Msh4 protein functions in chromosome synapsis and the regulation of crossover distribution. Genetics 158: $1013-1025$.

Offenberg, H.H., Schalk, J.A.C., Meuwissen, R.L.J., van Aalderen, M., Kester, H.A., Dietrich, A.J.J., and Heyting, C. 1998. SCP2: A major protein component of the axial elements of synaptonemal complexes of the rat. Nucleic Acids Res. 26: 2572-2579.

Page, S.L. and Hawley, R.S. 2001. c(3)G encodes a Drosophila synaptonemal complex protein. Genes \& Dev. 15:3130 3143.

- 2004. The genetics and molecular biology of the synaptonemal complex. Annu. Rev. Cell Dev. Biol. 20: 525-558.

Page, J., Suja, J.A., Santos, J.L., and Rufas, J.S. 1998. Squash procedure for protein immunolocalization in meiotic cells. Chromosome Res. 6: 639-642.

Pâques, F. and Haber, J.E. 1999. Multiple pathways of recombination induced by double-strand breaks in Saccharomyces cerevisiae. Microbiol. Mol. Biol. Rev. 63: 349-404.

Peters, A.H., Plug, A.W., van Vugt, M.J., and de Boer, P. 1997. A drying-down technique for the spreading of mammalian meiocytes from the male and female germline. Chromosome Res. 5: 66-68.

Pittman, D.L., Cobb, J., Schimenti, K.J., Wilson, L.A., Cooper, D.M., Brignull, E., Handel, M.A., and Schimenti, J.C. 1998. Meiotic prophase arrest with failure of chromosome synapsis in mice deficient for Dmcl, a germline-specific RecA homolog. Mol. Cell 1: 697-705.

Plug, A.W., Peters, A.H.F.M., Xu, Y., Keegan, K.S., Hoekstra, M.F., Baltimore, D., de Boer, P., and Ashley, T. 1997. ATM 
and RPA in meiotic chromosome synapsis and recombination. Nat. Genet. 17: 457-461.

Rogakou, E.P., Boon, C., Redon, C., and Bonner, W.M. 1999. Megabase chromatin domains involved in DNA doublestrand breaks in vivo. J. Cell Biol. 146: 905-915.

Ross-Macdonald, P. and Roeder, G.S. 1994. Mutation of a meiosis-specific MutS homolog decreases crossing over but not mismatch correction. Cell 79: 1069-1080.

Sage, J., Martin, L., Cuzin, F., and Rassoulzadegan, M. 1995. cDNA sequence of the murine synaptonemal complex protein 1 (SCP1) Biochim. Biophys. Acta 1263: 258-260.

Santucci, D.S., Walpita, D., Lespinasse, F., Desnuelle, C., Ashley, T., and Paquis-Flucklinger, V. 2000. MSH4 acts in conjunction with MLH1 during mammalian meiosis. FASEB $J$. 14: 1539-1547.

Shinohara, A. and Shinohara, M. 2004. Roles of RecA homologues Rad51 and Dmc1 during meiotic recombination. Cytogenet. Genome Res. 107: 201-207.

Snowden, T., Acharya, S., Butz, C., Berardini, M., and Fishel, R. 2004. hMSH4-hMSH5 recognizes Holliday junctions and forms a meiosis-specific sliding clamp that embraces homologous chromosomes. Mol. Cell 15: 437-451.

Storlazzi, A., Xu, L., Schwacha, A., and Kleckner, N. 1996. Synaptonemal complex (SC) component Zipl plays a role in meiotic recombination independent of SC polymerization along the chromosomes. Proc. Nat1. Acad. Sci. 93: 90439048.

Sun, H., Treco, D., and Szostak, J.W. 1991. Extensive 3'-overhanging, single-stranded DNA associated with the meiosisspecific double-strand breaks at the ARG4 recombination initiation site. Cell 64: 1155-1161.

Svetlanov, A. and Cohen, P.E. 2004. Mismatch repair proteins, meiosis, and mice: Understanding the complexities of mammalian meiosis. Exp. Cell Res. 296: 71-79.

Sym, M., Engebrecht, J.A., and Roeder, G.S. 1993. Zip1 is a synaptonemal complex protein required for meiotic chromosome synapsis. Cell 72: 365-378.

Tessé, S., Storlazzi, A., Kleckner, N., Gargano, S., and Zickler, D. 2003. Localization and roles of Ski8p protein in Sordaria meiosis and delineation of three mechanistically distinct steps of meiotic homolog position. Proc. Natl. Acad. Sci. 100: $12865-12870$.

Turner, J.M.A., Aprelikova, O., Xu, X., Wang, R., Kim, S., Chandramouli, G.V.R., Barrett, J.C., Burgoyne, P.S., and Deng, C.X. 2004. BRCA1, histone H2AX phosphorylation, and male meiotic sex chromosome inactivation. Curr. Biol. 14: 2135-2142.

Wang, T.F., Kleckner, N., and Hunter, N. 1999. Functional specificity of MutL homologs in yeast: Evidence for three Mlh1-based heterocomplexes with distinct roles during meiosis in recombination and mismatch correction. Proc. Nat1. Acad. Sci. 96: 13914-13919.

Wiltshire, T., Park, C., Caldwell, K.A., and Handel, M.A. 1995. Induced premature G2/M-phase transition in pachytene spermatocytes includes events unique to meiosis. Dev. Biol. 169: $557-567$.

Xu, L., Weiner, B.M., and Kleckner, N. 1997. Meiotic cells monitor the status of the interhomolog recombination complex. Genes \& Dev. 11: 106-118.

Yoshida, K., Kondoh, G., Matsuda, Y., Habu, T., Nishimune, Y., and Morita, T. 1998. The mouse RecA-like gene Dmcl is required for homologous chromosome synapsis during meiosis. Mol. Cell 1: 707-718.

Zickler, D. and Kleckner, N. 1999. Meiotic chromosomes: Integrating structure and function. Annu. Rev. Genet. 33: 603754. 


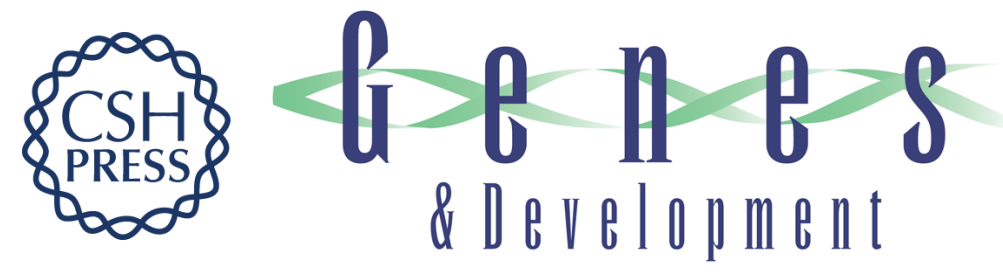

\section{Mouse Sycp1 functions in synaptonemal complex assembly, meiotic recombination, and $\mathrm{XY}$ body formation}

Femke A.T. de Vries, Esther de Boer, Mike van den Bosch, et al.

Genes Dev. 2005, 19:

Access the most recent version at doi:10.1101/gad.329705

Supplemental http://genesdev.cshlp.org/content/suppl/2005/06/06/19.11.1376.DC1
Material

References This article cites 56 articles, 20 of which can be accessed free at: http://genesdev.cshlp.org/content/19/11/1376.full.html\#ref-list-1

License

Email Alerting

Receive free email alerts when new articles cite this article - sign up in the box at the top

Service

right corner of the article or click here.

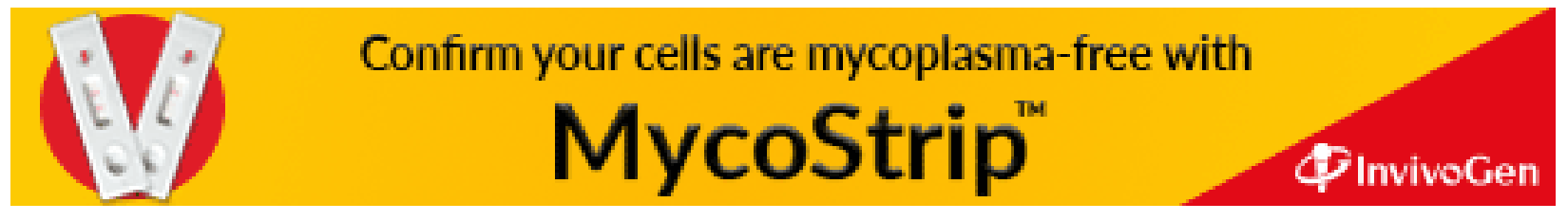

